\title{
Synthesis of Antioxidant and Evaluation of Its Oxidation Stability for Biodiesel
}

\author{
Soo-Youl Park ${ }^{\dagger}$, Seung-Rim Shin, Joung-II Shin, Kyoung-Lyong An and Kun Jun \\ Interface Chemistry and Engineering Research Team, \\ Green Chemistry Engineering Division, Korea Research Institute of Chemical Technology \\ (Received September 1, 2013 ; Revised October 10, 2013 ; Accepted October 16, 2013)
}

\begin{abstract}
Biodiesel fuels contain unsaturated fatty acid ester, which can easily oxidize, especially when exposed to ultraviolet light. The products formed by this oxidation give rise to sediment or gum formation. As a result, the fuel can contribute to the corrosion and plugging of the filter pump. Antioxidants have been used in an effort to stabilize biodiesels, but there is still a need for a biodiesel composition with improved oxidation stability. In general, good fuel compositions should provide synergistic combinations of a biodiesel and antioxidants. Our work involved the synthesis of antioxidants to improve the oxidative stability of biodiesel fuel.
\end{abstract}

Keywords - antioxidant, biodiesel, oxidative stability

\section{Introduction}

Biodiesel is a natural substitute for petroleum diesel that may be produced from renewable resources such as vegetable oils, animal fats and used cooking oil [1-4]. Chemically, the biodiesel as alkyl-esters from fatty acids derived from naturally occurring lipids, which may be produced, along with glycerin, through the reaction of tri-acylglycerides with ethanol or methanol, in the presence of an acid or base catalyst [5].

Biodiesel has great potential as an alternative fuel for compression ignition engines, and one of its great advantages is that it is similar to diesel fuel. Homogeneous and oxygen content structure gives good combustion properties and oxygen gives it excellent properties for environment and fuel lubricity. Also, biodiesel is easy to handle because its boiling point is higher than that of diesel and it is an environment-friendly fuel with low smoke emissions because it contains $10 \%$

Corresponding author : sypark@krict.re.kr

Tel: +82-(0)42-860-7666

Fax: $+82-(0) 42-860-7669$ oxygen. In addition, biodiesel has a higher specific gravity and higher kinematic viscosity than diesel; the higher cetane number of biodiesel can shorten the ignition delay, reducing the NOx emissions during the initial combustion process. Biodiesel also emits lower levels of hydrocarbons (HC), $\mathrm{CO}$, polycyclic aromatic hydrocarbons (PHA), $\mathrm{SO}_{2}$, and smoke than diesel.

The oxidation stability of biodiesel must be a concern for both producers and future consumers of this product. This is because oxidative processes promote increased viscosity through the occurrence of condensation reactions involving double bonds. These reactions can be lead to the formation of insoluble materials, such as gums and sediments that plug fuel filters and injection systems [6-7]. Given that factors such as the presence of be lead to the formation of insoluble materials, such as gums and sediments that plug fuel filters and injection systems [6-7]. Given that factors such as the presence of air, heat, light and pro-oxidants such as hydroperoxides and metals are known to be responsible for the onset of oxidation reactions. In this content, the use of effective antioxidants that increase the stability of biodiesel, is of fundamental importance to maintain- 




Fig. 1. The chemical structure of bio diesel.

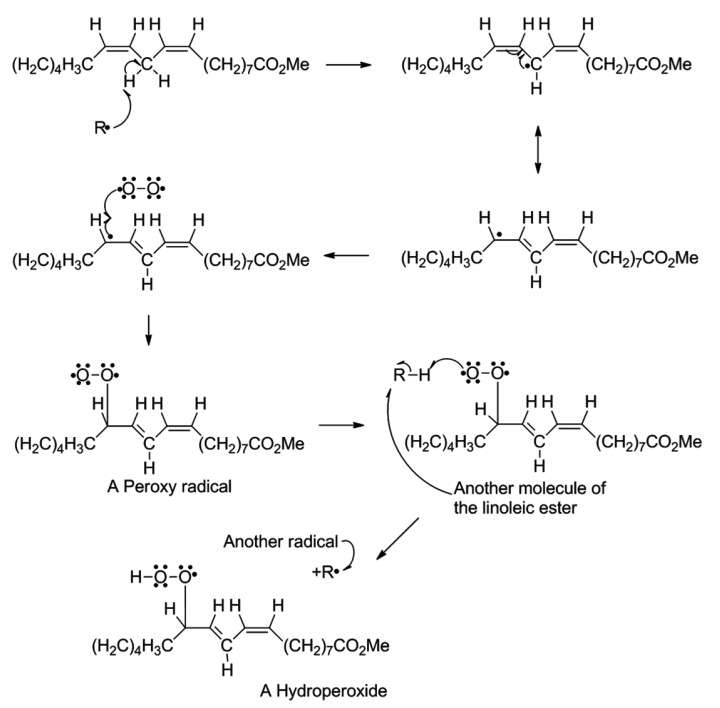

Scheme 1. The antioxidation mechanism for biodiesel.

ing a program, aimed at its production and use. When exposed to air during storage, autoxidation of biodiesel can cause degradation of fuel quality. One approach for increasing resistance of fatty derivatives against is to treat them with oxidation inhibitors, i.e. antioxidants. Alkylphenols are valuable industrial chemicals, among which t-butylated phenols are of particular importance [8-10]. This study examines the effectiveness of such antioxidants, t-butylhydroquinone (TBHQ), butylated hydroanisole (BHA), n-propyl gallate (PrG), pyrogallol (PyG) in biodiesel.

This study investigates the oxidation stability of biodiesels made from used edible frying oils using the

Rancimat test, as recommended in European Normalization(EN) 14214. The effects of antioxidants in biodiesels on engine performance, combustion characteristics, and exhaust emissions are also studied.

\section{Experiments}

\section{2-1. Materials and analytical methods}

All solvents, reagents and starting materials were purchased and used without further purification. All chemical agents were purchased from Aldrict. ${ }^{1} \mathrm{H}$ NMR spectra was recorded on a Bruker Advance DRX 400 spectrometer at 300 and $500 \mathrm{MHz}$, respectively. Samples were run in $\mathrm{CDCl}_{3}$ or DMSO-d and referenced to TMS. Melting points were recorded on a Buchi Melting Point B-544. GC analyses were carried out using a Hewlett Packard Series 5890 equipped with a DB-1 fused silica coloumn $(25 \mathrm{~m} \times 0.32 \mathrm{~mm}$ id, $0.5 \mu \mathrm{m}$ film thickness). The injector and detector temperatures were 250 and $290^{\circ} \mathrm{C}$, respectively. The oven temperature was programmed as follow: initially $80^{\circ} \mathrm{C}$, increasing to $290^{\circ} \mathrm{C}$ at $10^{\circ} \mathrm{C} \mathrm{min}$ and holding for $10 \mathrm{~min}$.

\section{2-2. Experiments methods}

2-2-1. The synthesis of 2-t-butylhydroquinone

A typical experiment procedure for alkylation of hydroquinone is as follows. $66 \mathrm{~g}$ of hydroquinone (0.6 mole) and $240 \mathrm{ml}$ of phosphoric acid were dissolved in toluene. A solution $60 \mathrm{ml}$ of tert-butanol ( 0.6 mole) was placed in a dropping funnel and was added to the reaction mixture dropwise maintaining the reaction temperature about $110^{\circ} \mathrm{C}$ over a period of 1 to 2 hours. The reaction mixture was stirred further about $110^{\circ} \mathrm{C}$ for one hour. The reaction is monitored by thin layer chromatography. After separated phosphoric acid layer off, the reaction mixture is cooled to room temperature and the solvent was removed from organic phase under reduced pressure. The solid separated was 
purified by a mixture of toluene and dioxane. Mass spectrum (EI); found $\mathrm{M}=166$, required for $\mathrm{M}=166$, Anal. Calcd for $\mathrm{C}_{10} \mathrm{H}_{14} \mathrm{O}_{2}$ : C, 72.26; H, 8.49. Found: $\mathrm{C}$, 71.83; H, 8.43. ${ }^{1} \mathrm{HNMR}\left(300 \mathrm{MHz}, \mathrm{CDCl}_{3}\right): \delta$ (ppm) $1.36(\mathrm{~s}, 9 \mathrm{H}), 6.52(\mathrm{~d}, 2 \mathrm{H}, \mathrm{J}=1.65 \mathrm{~Hz}), 6.75(\mathrm{t}, \mathrm{H}, \mathrm{J}=1.80$ $\mathrm{Hz}), 10.10(\mathrm{~s}, \mathrm{H}), 11.20(\mathrm{~s}, \mathrm{H})$.

\section{2-2-2. The synthesis of 2-t-butylhydroanisole}

$166 \mathrm{~g}$ of 2-t-butylhydroquinone were dissolved in $996 \mathrm{ml}$ hexane and was added $159.3 \mathrm{~g}$ of dimethyl sulphate with stirring for 20 minutes. A solution of $55.6 \mathrm{~g}$ sodium hydroxide in $111 \mathrm{ml}$ water was placed in a dropping funnel and was added to the reaction mixture drop-wise maintaining the reaction temperature below $45-50^{\circ} \mathrm{C}$ over a period of 1 to 3 hours. The reaction is monitored by thin layer chromatography. After the addition is over, reaction mixture is cooled to room temperature and adjusted to $\mathrm{pH}$ of 3 to 4 with $50 \%$ sulphuric acid. Aqueous layer was separated and discarded. The hexane layer was washed with $250 \mathrm{ml}$ water and further it was optionally washed with sodium hydroxide solution. The total hexane layer was removed from organic phase under reduced pressure and the solid filtered was filtered and washed with hexane. The solid filtered was sucked dry and the product obtained was colorless solid form. Mass spectrum (EI); found $\mathrm{M}=180$, required for $\mathrm{M}=180$, Anal. Calcd for $\mathrm{C}_{11} \mathrm{H}_{16} \mathrm{O}_{2}$ : C, 73.30; H, 8.95. Found: C, 73.39; $\mathrm{H}, 8.89 .{ }^{1} \mathrm{HNMR}\left(300 \mathrm{MHz}, \mathrm{CDCl}_{3}\right): \delta(\mathrm{ppm}) 1.41(\mathrm{~d}$, $9 \mathrm{H}, J=9.30 \mathrm{~Hz}), 3.72(\mathrm{~s}, 3 \mathrm{H}), 6.60(\mathrm{~d}, 2 \mathrm{H}, J=1.50 \mathrm{~Hz})$, $6.86(\mathrm{t}, \mathrm{H}, J=2.80 \mathrm{~Hz}), 10.32(\mathrm{~s}, \mathrm{H})$.

\section{2-2-3. The synthesis of propyl gallate}

$37.6 \mathrm{~g}$ of gallic acid $(0.2 \mathrm{~mole}), 4 \mathrm{ml}$ of sulfuric acid and were dissolved in toluene. A $96 \mathrm{ml}$ of n-propyl alcohol (1.3 mole) was placed in a dropping funnel and was added to the reaction mixture dropwise. The reaction mixture was stirred further about 100 for 16 hours. The reaction is monitored by thin layer chromatography. After the reaction mixture is cooled to room temperature and the solvent was removed from organic phase under reduced pressure. The solid separated was purified by a mixture of ethanol and water.
The solid filtered was sucked dry and the product obtained was colorless solid form. Mass spectrum(EI); found $M=212$, required for $M=212$, Anal. Calcd for $\mathrm{C}_{10} \mathrm{H}_{12} \mathrm{O}_{5}$ : C, 56.60; H, 5.70. Found: C, 56.40; H, 5.67. ${ }^{1} \mathrm{H}$ NMR (300 MHz, DMSO-d ${ }_{6}$ ) 0.93(t, $3 \mathrm{H}, J=7.50 \mathrm{~Hz}$ ), 1.67(quart, $2 \mathrm{H}, J=7.20 \mathrm{~Hz}$ ), $4.10(\mathrm{t}, 2 \mathrm{H}, J=6.60 \mathrm{~Hz}$ ), 6.93(s, 2H), 8.90(s, H), 9.23(s, 2H)

\section{2-2-4. The synthesis of pyrogallol}

$26 \mathrm{~g}$ of gallic acid $(0.15 \mathrm{~mole})$ and $50 \mathrm{ml}$ of distillated water was placed in Autoclave chamber. The reaction mixture was stirred further about 190 for 4 hours. The reaction is monitored by thin layer chromatography. After the reaction mixture is cooled to room temperature and the solid precipitated was separated from $50 \mathrm{ml}$ of ethyl formate organic phase. After the organic ethyl formate layer was removed under reduced pressure, the solid filtered was filtered and washed with distillated water. The solid filtered was sucked dry and the product obtained was colorless solid form. Mass spectrum(EI); found $\mathrm{M}=126$, required for $\mathrm{M}=126$, Anal. Calcd for $\mathrm{C}_{6} \mathrm{H}_{6} \mathrm{O}_{3}: \mathrm{C}, 57.14 ; \mathrm{H}, 4.80$. Found: C, 57.40; H, 5.03. 'H NMR (300 MHz, DMSO$\left.\mathrm{d}_{6}\right) 6.22(\mathrm{~d}, 2 \mathrm{H}, J=8.10 \mathrm{~Hz}), 6.39(\mathrm{dd}, \mathrm{H}, J=7.50 \mathrm{~Hz})$, 7.99(s, H) 8.71(s, 2H)

\section{Results and Discussion}

The general reaction scheme is given in Scheme 1. The t-butylation of hydroquinone with t-butanol or isobutylene is an electrophilic substitution reaction on the aromatic ring. In the presence of acid catalyst, $\mathrm{H}_{3} \mathrm{PO}_{4}$ is used for the production of t-butylhydroquinone while for the synthesizing 2,5-di-t-butylhydroquinone the reaction occurs in the presence acid condition.

The general reaction scheme is given in Scheme 2. The tert-butylation of hydroquinone with tert-butanol is an electrophilic substitution reaction on the aromatic ring commonly via a carbenium ion mechanism. In the presence of acid catalyst at high temperatures, tertbutanol gets dehydrated into isobutylene and water. Isobutylene is subsequently protonated by the acid cat- 


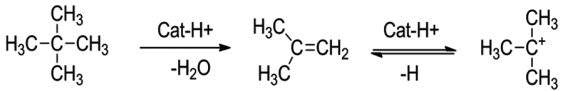

$$
\begin{aligned}
& \text { (c) }
\end{aligned}
$$

Scheme 2. Reaction mechanism of tert-butylation of hydroquinone.

alysts to form tert-butyl carbenium[11], which further reacts with hydroquinone to generate 2-tert-butyl hydroquinone (2-TBHQ) and 2,5-di-tert-butyl hydroquinone (2,5-DTBHQ). No O-alkylation products were found and Badamali et al. [12] considered that only weak acid sites can favor formation of O-alkylation product, and Yadav et al. [13] thought that the ratio of different products depends on the nature of catalysts and reaction conditions used for alkylation.

A Model 743 Rancimat (Metrohm, Herisau, Switzerland) was used to measure the thermal oxidation stability. Over time, oxygen breaks down fats and volatile acids formed, affecting the consistency and taste of a product. The 743 Rancimat accelerates this process by exposing the sample to elevated temperatures while pumping air into it. The induction time, calculated automatically, is usually a few hours instead of weeks or months, and the time correlates to the years of life of a product. The Rancimat oxidative stability

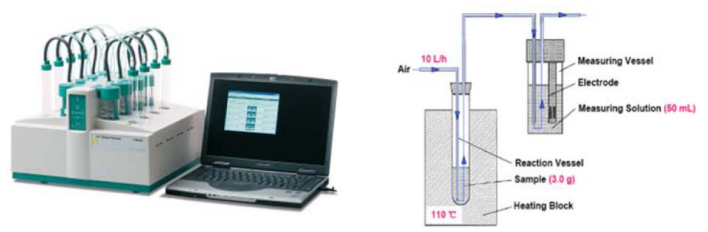

Fig. 2. The oxidation instrument for the Rancimat 743.

Table 2. The oxidation stability of hydroquinone typed and galate typed antioxidants

\begin{tabular}{ccccc}
\hline \hline Compounds & BD100 & $250 \mathrm{ppm} / \mathrm{hr}$ & $500 \mathrm{ppm} / \mathrm{hr}$ & $750 \mathrm{ppm} / \mathrm{hr}$ \\
\hline TBHQ & 3.8 & 16.9 & 22.8 & 27.4 \\
\hline PyG & 2.7 & 12.1 & 15.0 & 15.9 \\
\hline PrG & 3.8 & 8.2 & 10.4 & 12.1 \\
\hline TBHA & 3.8 & 6.7 & 8.9 & 9.6 \\
\hline
\end{tabular}

method allows us to test the effectiveness of antioxidants, determine a produce effectiveness of antioxidants, determine a product's shelf life, and test the stability of new ingredients.

We evaluated the effect of antioxidants on the oxidation stability of biodiesels. The quantity of antioxidant added was 0, 250. 500, 750 ppm by weight. After determining that the antioxidants were soluble in biodiesel, the test fuels were sampled to examine their oxidation stability. The oxidation stability of the biodiesels was evaluated with a Rancimat 743(Metrohm Herisau, Switzerland) applying the accelerated oxidation test specified in EN 14214 [14]. The Rancimat (EN 14214) method specifies that samples are to be analyzed at 110 (block temperature) with an air flow rate of $10 \mathrm{~L} / \mathrm{h}$ through the sample.

Fig. 3 shows the effect of antioxidants on the oxida-

Table 1. Physical characterization data of antioxidant compounds

\begin{tabular}{cccccc}
\hline \hline Antioxidant & $\begin{array}{c}\text { Reaction } \\
\text { material }\end{array}$ & $\begin{array}{c}\text { Reaction temp. } \\
\left({ }^{\circ} \mathrm{C}\right)\end{array}$ & $\begin{array}{c}\text { Reaction time } \\
(\mathrm{hr})\end{array}$ & $\begin{array}{c}\text { Yield } \\
(\%)\end{array}$ & $\begin{array}{c}\text { Purity } \\
(\mathrm{EA}, \%)\end{array}$ \\
\hline TBHQ & $\mathrm{t}-\mathrm{BuOH}, \mathrm{H}_{3} \mathrm{PO}_{4}$ & reflux & 1 & 40 & 99 \\
\hline TBHA & $\left(\mathrm{CH}_{3} \mathrm{O}\right)_{2} \mathrm{SO}_{2}$ & 50 & $1 \sim 2$ & 84 & 99 \\
\hline $\mathrm{PrG}$ & $\mathrm{PrOH}$ & reflux & 16 & 86 & 99 \\
\hline PyG & $\mathrm{H}_{2} \mathrm{O}$ & 190 & 4 & 80 & 96 \\
\hline
\end{tabular}




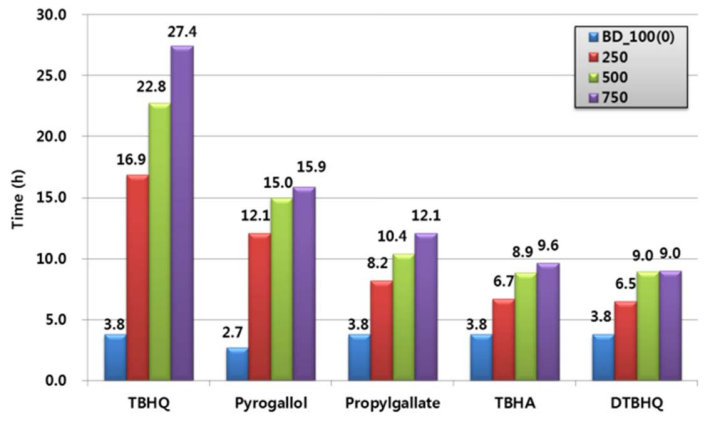

Fig. 3. The oxidation stable effects of antioxidants in biodiesel.

tion stability of biodiesel fuels. The efficiency of the antioxidants on the oxidation stability in this works was in the order TBHQ $>$ PyG $>$ PrG $>$ TBHA in weight of $500 \mathrm{ppm}$.

\section{Conclusion}

The antioxidants of hydroquinone typed were produced by electrophilic substitution reaction in acid catalyst. The other antioxidants of gallic acid typed were obtained by reacting of absolute alcohol or high temperature and autoclave was introduced preferably by $\mathrm{CO}_{2}$ emission.

Among the synthetic antioxidants evaluated for the increased stability of biodiesels. TBHQ offered the best oxidation stability for all the biodiesel in concentrations ranging from 250 to $700 \mathrm{ppm}$. The synthetic antioxidants, especially, TBHQ and PrG were more effective than the other antioxidants such as BHA and BHT. The efficiency of the antioxidants investigated in this study was in the order TBHQ $>$ PyG $>$ PrG $>$ TBHA $>$ DTBHQ. Finally, our research studies have been aimed at the use of these antioxidants materials for automotive or energy-related purposes.

\section{References}

[1] Ferrari, L. P., Oliveira, V. S. and Scabio, A., Quim. Nova, Vol. 28, pp. 19, 2005.

[2] Pinto, A. C., Guarieiro, L. L., Rezande, M. J. C., Ribeiro, N. M., Torres, E. A., Lopes, W. A., Pereira, P. A. P., de Andrade, J. B., J. Braz, Chem. Soc., Vol. 16, 1313, 2005.

[3] Schuchardt, U., Sercheli, R., Vargas, R. M., J. Braz. Chem. Soc., Vol. 9, pp. 199, 1998.

[4] Zagonel, G. F., Ramos, L. P., Rev, Quim. Ind., Vol. 717, pp. 17, 2001.

[5] Gunstone, F. D., The Chemistry of Oil and Fats, Blackwell Publishing; Boca Raton, 2004.

[6] Monyem, A., Van Gerpen, J. Biomass and Bioenergy, Vol. 20, pp. 317, 2001.

[7] Tao, Y, Operation of Cummins N-14 Diesel on Biodiesel; Performance Enissions and Durability, Final Report to the National Biodiesel Board, Ortech Report No. 95-E11-B004524, 1995.

[8] M. D. Shahid, US Patent. 6,525,146.

[9] M. Blum and M. Roitberg, US patent. 5,958,479.

[10] B. Nager, WO 90/00015.

[11] Selvarai M, Jean SH, Han J, Sinha PK, Lee TG, Appl Catal A Gen, Vol. 286, pp. 44, 2005.

[12] Badamali S.K., Sakthivel A, Selvam P, Catal. Lett., Vol. 65, pp. 153, 2000.

[13] Yadav G.D. Kirthivasan N, Appl Catal A, Vol. 154, pp. 29, 2000, Yadav G.D. Kirthivasan N, Appl Catal A, Gen., Vol. 286, pp. 61, 2005.

[14] Fat and oil derivatives, Fatty acid methyl esters (FAME)-Dertermimation of oxidation stability, EN 14214, 2003. 